\title{
A New Early Gastric Cancer after Subtotal Gastric Resection for Early Cancer: Case Report and Review of the Literature
}

\author{
Lorenzo Bruno ${ }^{*}$, Lucia Barni ${ }^{1}$, Gabriella Nesi², Sabrina Pacciani' ${ }^{1}$, Gaia Masini ${ }^{1}$, \\ Filippo Melli' ${ }^{1}$, Gherardo Maltinti' ${ }^{1}$, Tiku Zalla ${ }^{1}$, Lorenzo Dioscoridi', \\ Antonio Taddei ${ }^{1}$, Giancarlo Freschi' ${ }^{1}$, Paolo Bechi ${ }^{1}$ \\ ${ }^{1}$ Department of Surgery and Translational Medicine, University of Florence, Florence, Italy \\ ${ }^{2}$ Division of Pathological Anatomy, Department of Surgery and Translational Medicine, University of Florence, \\ Florence, Italy \\ Email: ${ }^{\text {Ibruno@katamail.com }}$
}

Received 10 October 2014; revised 14 November 2014; accepted 23 November 2014

Academic Editor: Sibu P. Saha, University of Kentucky, USA

Copyright (C) 2014 by authors and Scientific Research Publishing Inc.

This work is licensed under the Creative Commons Attribution International License (CC BY).

http://creativecommons.org/licenses/by/4.0/

(c) (i) Open Access

\begin{abstract}
Although the prognosis of early gastric cancer (EGC) is considered to be satisfactory, some patients experience tumor relapse after curative surgery. Both pathogenesis and risk factors of recurrence remain unclear. We describe a case report of a 49-year-old male who underwent subtotal gastric resection D2A for angular gastric cancer. Histological examination revealed gastric adenocarcinoma with low grade of differentiation and colloid areas, intramucosal, and absence of neoplastic proliferation in the surgical margins, in omental stroma and in the six examined lymph nodes (pT1, pN0). 11 years later, the same patient underwent D2 total gastrectomy for gastric cancer in the remnant stomach. New histological examination revealed again gastric adenocarcinoma, intramucosal, medium degree of differentiation, no documentable neoplastic proliferation within the limits of surgical resection, in the thirty-three examined lymph nodes and in the omentum (pT1, pN0).
\end{abstract}

\section{Keywords}

Early Gastric Cancer, Remnant Gastric Cancer, Long Term Follow-Up

\footnotetext{
${ }^{*}$ Corresponding author.
}

How to cite this paper: Bruno, L., et al. (2014) A New Early Gastric Cancer after Subtotal Gastric Resection for Early Cancer: Case Report and Review of the Literature. Journal of Cancer Therapy, 5, 1450-1453. 


\section{Introduction}

Early gastric cancer (EGC) is defined as gastric carcinoma confined to the mucosa and/or submucosa irrespective of lymph node involvement and tumor size [1]. Compared to advanced gastric cancer, EGC has a more favourable prognosis after curative resection, with 5-year survival rates exceeding 90\% in Japan, Korea and slightly lower in Italy, France and US [2] [3]. In spite of the favorable prognosis, tumor recurrence or a second primary cancer may occur in certain patients after curative surgery (with the recurrence or second primary cancer rate varying from $1.4 \%$ to $13.7 \%$ ) [4]. In view of the trend to a lower risk of recurrence when more than 15 nodes are retrieved, D2 lymphadenectomy is considered the treatment of choice [5]. EGC with lymph node metastasis has a higher possibility of recurrence, especially with $>6$ positive lymph nodes [6]. These patients could be considered as a high risk group and candidates for adjuvant treatment such as chemotherapy. We herein describe a case report of a patient who underwent total gastrectomy for EGC 11 years after gastric resection for EGC.

\section{Clinical Summary}

In July 2003, a 49-year-old man underwent subtotal gastric resection for angular gastric cancer. Familiar history of colon neoplasia was reported. Histological examination revealed gastric adenocarcinoma with low grade of differentiation, colloid areas (Lauren: mixed type, intestinal and diffuse), intramucosal (Kodama: small-m). No documentable neoplastic proliferation within the limits of surgical resection, in the six examined lymph nodes and in the omentum (pT1, pN0). After surgery, the patient continued follow-up for 11 years according to this schedule: clinical examination, abdomen ultasuond and laboratory investigations every 6 months and periodic endoscopic examinations of the gastric remnant (EGDS: 2006-2009-2014). In 2012, he underwent prostatectomy for prostate cancer (T2, N0) and in 2013 he underwent laparoscopic colecystectomy. In June 2014 the patient was asymptomatic for pain, thickening or anemia but EGDS showed mucosal fragility at the anastomotic site, that was frail and spontaneously bleeding. Some biopsies were performed. Histological examination reported: signet ring cell cancer with low grade of differentiation, involving mucosal layer. The patient underwent abdominal CT, that resulted negative for secondary liver lesions. Gastric stump presented a parietal thickening $(10 \mathrm{~mm})$ at anastomosis level, extended for around $28 \mathrm{~mm}$. Adjacent tissue, peri-gastric and intra-abdominal lymph nodes were not infiltrated. Tumor markers were negative. The patient underwent D2 total gastrectomy. Histological examination reported: intramucosal gastric adenocarcinoma, medium degree of differentiation, no documentable neoplastic proliferation in the surgical margins, in the thirty-three examined lymph nodes and in the omentum (pT1, pN0; Kodama: small-m). Based on the clinical course and pathological-futures, we concluded that the patient had a new cancer and not a local recurrence.

\section{Discussion}

Early gastric cancer patients have a good prognosis after radical resection. However, if the patients have a gastric remnant, the risk of metachronous gastric cancer remains, is still higher [7]. For early detection and curative treatment of metachronous gastric cancer, periodic endoscopic examinations of the gastric remnant are extremely important. It is necessary to clarify the risk factors of metachronous gastric cancer to develop an optimal endoscopic surveillance program. Recent advances in diagnostic technique had led to a higher detection rate of early remnant gastric cancer following distal gastrectomy [8] [9]. In a previous study [7], out of 26 previously resected for EGC patients, who underwent remnant gastrectomy for cancer, 23 (88.5\%) were T1, none with nodal metastases. Recurrence and second primary cancers occurred in $2.8 \%$ and $5.0 \%$ respectively of patients with early gastric cancer, mostly within 10 years since the original surgical treatment, in particular lung and colon cancer, instead more than 10 years after surgery is most frequent the gastric remnant cancer [10] [11]. Most metachronous gastric cancers in the remnant stomach following gastric cancer surgery are thought to derive from multicentric carcinogenesis, but some may be lesion that were missed at the time of diagnosis of the primary EGC [12]-[14]. Typically, a secondary methacronous gastric cancer develops within 10 years since the primary surgery. Many studies have been published on patient treated for benign gastric disease, and gastric resection is considered to be a risk factors for gastric stump carcinoma even 15 - 20 years after surgical treatment, especially when Billroth 2 reconstruction was performed [15]-[17]. A Komatsu's study shows that after Billroth I reconstruction, remnant gastric cancer occurred more frequently near the suture line and remnant gastric wall; after Billroth II reconstruction, remnant gastric cancer occurred more frequently at the anastomotic site with a 
longer interval between surgical procedures [9]. For patients treated for malignancy it is still not clear when gastric stump cancer should be considered a recurrence or a new carcinoma arising on the stump. Some authors define new lesion in the remnant stomach using the following two criteria: firstly, that curative surgery of the initial cancers had been carried out, with adequate surgical margins; secondly, that the invasion by the secondary cancers was larger on the mucosal side than on the serosal side or the peritoneum [18]. According to a 2010 study published by JGC, it is rather clear that, when compared to patients undergoing gastric resection for benign disease, the interval from the first operation to the diagnosis of remnant gastric cancer for patients with primary malignant disease is shorter and the TNM stage is less advanced. This is probably because regular follow-up such as endoscopy was less commonly performed in the patient with benign primary disease, and so more advanced remnant gastric cancer was detected [19]. Anyway age, male sex, Lauren intestinal histotype, submucosal invasion and nodal status have been identified as the most important risk factors [20]. Hereditary diffuse gastric cancer (HDGC), the only gastric cancer syndrome with a proven inherited defect, caused by germline E-cadherin/CDH1 alterations, presents a rather different pattern [8]. Furthermore the detection of the same histopathological features in both tumors, suggests that specific precancerous conditions going through individual pathways are involved in the development of remnant gastric cancer.

\section{Conclusion}

We describe a case of a patient who made a new early gastric cancer after surgery for early gastric cancer. Male sex and Lauren intestinal histotype are confirmed as important risk factors for developing a second primary cancer. So in agreement with the literature we can say that long-term endoscopic follow-up is necessary to locate metachronous gastric cancer in the remnant stomach at its early stage, particularly in male patients whose cancers are of the intestinal type.

\section{References}

[1] Japanese Gastric Cancer Association (1998) Japanese Classification of Gastric Carcinoma. 2nd English Edition. Gastric Cancer, 1, 10-24. http://dx.doi.org/10.1007/PL00011681

[2] Degiuli, M. and Calvo, F. (2006) Survival of Early Gastric Cancer in a Specialized European Center. Which Lymphadenectomy Is Necessary? World Journal of Surgery, 30, 2193-2203. http://dx.doi.org/10.1007/s00268-006-0179-1

[3] Borie, F., et al. (2004) Prognostic Factors for Early Gastric Cancer in France: Cox Regression Analysis of 332 Cases. World Journal of Surgery, 28, 686-691. http://dx.doi.org/10.1007/s00268-004-7127-8

[4] Huang, B., et al. (2011) Long-Term Survival Results and Prognostic Factors of Early Gastric Cancer. Experimental and Therapeutic Medicine, 2, 1059-1064.

[5] Roviello, F., et al. (2006) Number of Lymph Node Metastases and Its Prognostic Significance in Early Gastric Cancer: A Multicenter Italian Study. Journal of Surgical Oncology, 94, 275-280. http://dx.doi.org/10.1002/jso.20566

[6] Lee, H.J., et al. (2003) Clinicopathological Analysis for Recurrence of Early Gastric Cancer. Japanese Journal of Clinical Oncology, 33, 209-214. http://dx.doi.org/10.1093/jjco/hyg042

[7] Nozaki, I., et al. (2010) Risk Factors for Metachronous Gastric Cancer in the Remnant Stomach after Early Cancer Surgery. World Journal of Surgery, 34, 1548-1554. http://dx.doi.org/10.1007/s00268-010-0518-0

[8] Oliveira, C., et al. (2013) E-Cadherin Alterations in Hereditary Disorders with Emphasis on Hereditary Diffuse Gastric Cancer. Progress in Molecular Biology and Translational Science, 116, 337-359. http://dx.doi.org/10.1016/B978-0-12-394311-8.00015-7

[9] Komatsu, S., et al. (2012) Progression of Remnant Gastric Cancer Is Associated with Duration of Follow-Up Following Distal Gastrectomy. World Journal of Gastroenterology, 18, 2832-2836. http://dx.doi.org/10.3748/wjg.v18.i22.2832

[10] Ikeda, Y., et al. (2005) Effective Follow-Up for Recurrence or a Second Primary Cancer in Patients with Early Gastric Cancer. British Journal of Surgery, 92, 235-239. http://dx.doi.org/10.1002/bjs.4758

[11] Yamamoto, M., Yamanaka, T., Baba, H., Kakeji, Y. and Maehara, Y. (2008) The Postoperative Recurrence and the Occurrence of Second Primary Carcinomas in Patients with Early Gastric Carcinoma. Journal of Surgical Oncology, 97, 231-235. http://dx.doi.org/10.1002/jso.20946

[12] Nasu, J., Doi, T., Endo, H., Nishina, T., Hirasaki, S. and Hyodo, I. (2005) Characteristics of Metachronous Multiple Early Gastric Cancers after Endoscopic Mucosal Resection. Endoscopy, 37, 990-993.

http://dx.doi.org/10.1055/s-2005-870198 
[13] Kang, G.H., Kim, C.J., Kim, W.H., Kang, Y.K., Kim, H.O. and Kim, Y.I. (1997) Genetic Evidence for the Multicentric Origin of Synchronous Multiple Gastric Carcinoma. Laboratory Investigation, 76, 407-417.

[14] Ohtani, H., Yashiro, M., Onoda, N., Nishioka, N., Kato, Y., Yamamoto, S., et al. (2000) Synchronous Multiple Primary Gastrointestinal Cancer Exhibits Frequent Microsatellite Instability. International Journal of Cancer, 86, 678-683. http://dx.doi.org/10.1002/(SICI)1097-0215(20000601)86:5<678::AID-IJC12>3.0.CO;2-O

[15] Ahn, H.S., Kim, J.W., Yoo, M.W., Park, D.J., Lee, H.J., Lee, K.U. and Yang, H.K. (2008) Clinicopathological Features and Surgical Outcomes of Patients with Remnant Gastric Cancer after a Distal Gastrectomy. Annals of Surgical Oncology, 15, 1632-1639. http://dx.doi.org/10.1245/s10434-008-9871-8

[16] Ohashi, M., Katai, H., Fukagawa, T., Gotoda, T., Sano, T. and Sasako, M. (2007) Cancer of the Gastric Stump Following Distal Gastrectomy for Cancer. British Journal of Surgery, 94, 92-95. http://dx.doi.org/10.1002/bjs.5538

[17] Sinning, C., Schaefer, N., Standop, J., Hirner, A. and Wolff, M. (2007) Gastric Stump Carcinoma—Epidemiology and Current Concepts in Pathogenesis and Treatment. European Journal of Surgical Oncology, 33, 133-139. http://dx.doi.org/10.1016/j.ejso.2006.09.006

[18] Hosokawa, O., Kaizaki, Y., Watanabe, K., Hattori, M., Douden, K., Hayashi, H. and Maeda, S. (2002) Endoscopic Surveillance for Gastric Remnant Cancer after Early Cancer Surgery. Endoscopy, 34, 469-473. http://dx.doi.org/10.1055/s-2002-32007

[19] Lee, S.B., Kim, J.H., Kim, D.H., Jeon, T.Y., Kim, D.H., Kim, G.H. and Park, D.Y. (2010) Clinicopathological Characteristics and Prognosis of Remnant Gastric Cancer. Journal of Gastric Cancer, 10, 219-225. http://dx.doi.org/10.5230/jgc.2010.10.4.219

[20] Morgagni, P., Gardini, A., Marrelli, D., Vittimberga, G., Marchet, A., de Manzoni, G., et al. (2014) Gastric Stump Carcinoma after Distal Subtotal Gastrectomy for Early Gastric Cancer: Experience of 541 Patients with Long-Term Follow-Up. The American Journal of Surgery, in Press. http://dx.doi.org/10.1016/j.amjsurg.2014.06.021 
Scientific Research Publishing (SCIRP) is one of the largest Open Access journal publishers. It is currently publishing more than 200 open access, online, peer-reviewed journals covering a wide range of academic disciplines. SCIRP serves the worldwide academic communities and contributes to the progress and application of science with its publication.

Other selected journals from SCIRP are listed as below. Submit your manuscript to us via either submit@scirp.org or Online Submission Portal.
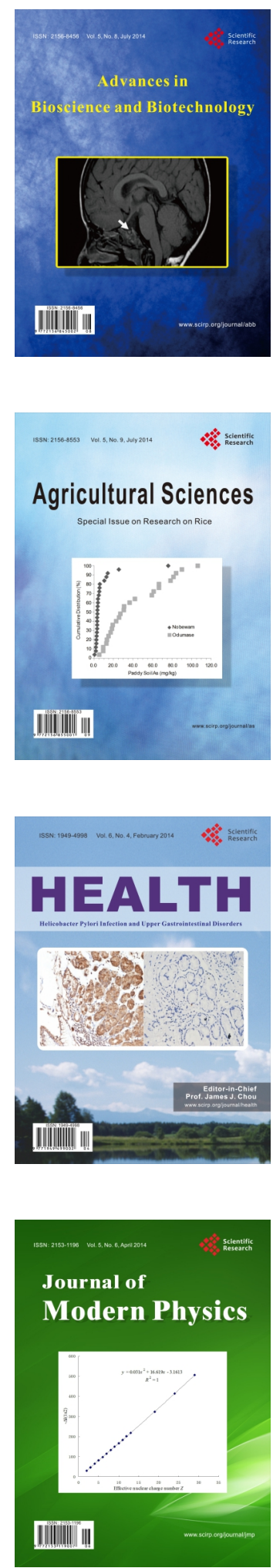
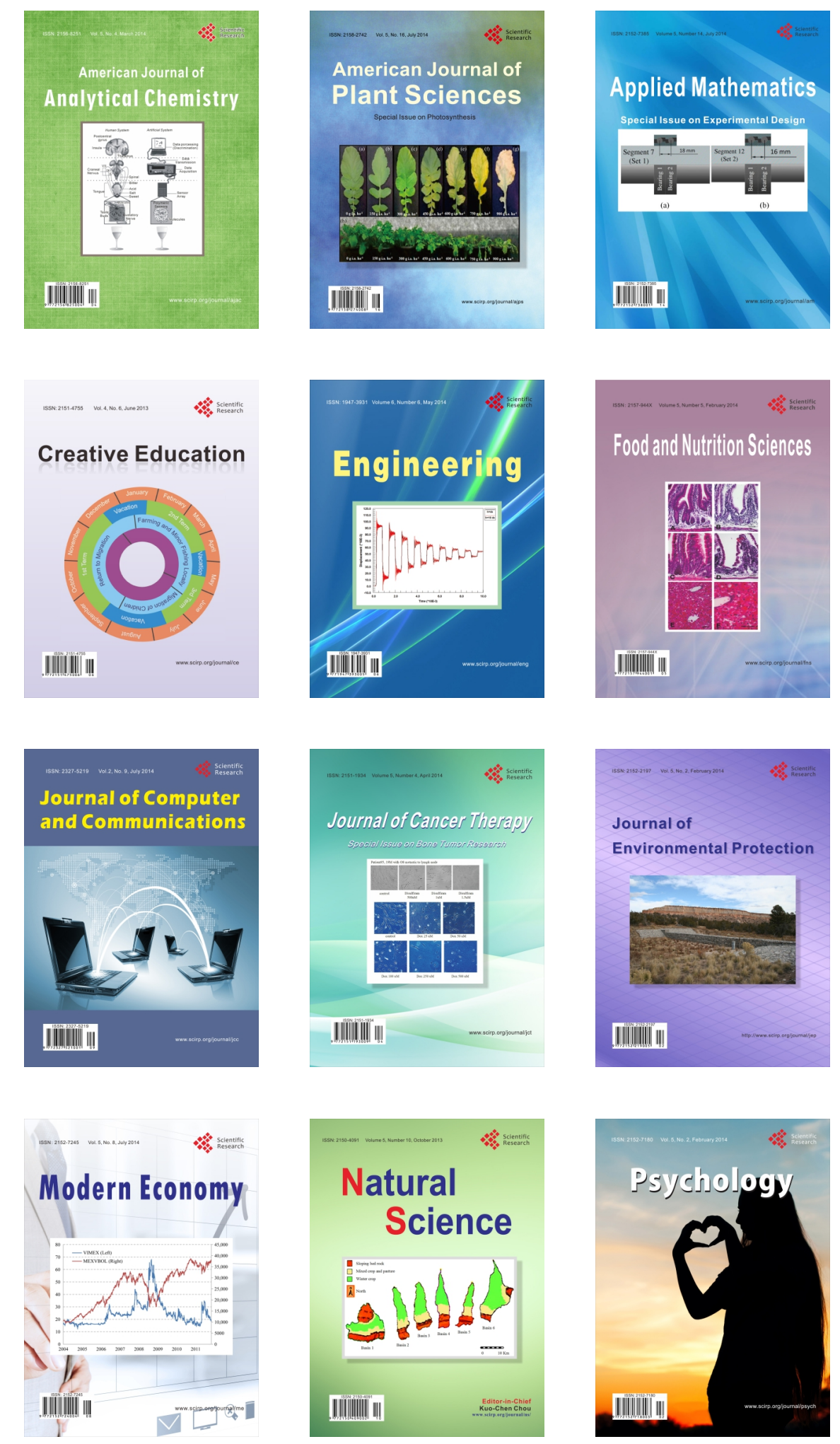